\title{
Interaction of Taste and Place Coding in the Hippocampus
}

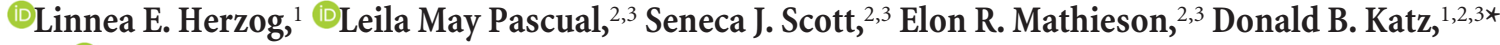 \\ and Shantanu P. Jadhav ${ }^{1,2,3 *}$ \\ ${ }^{1}$ Graduate Program in Neuroscience, Brandeis University, Waltham, Massachusetts 02453, ${ }^{2}$ Neuroscience Program, Department of Psychology, \\ and ${ }^{3}$ Volen National Center for Complex Systems, Brandeis University, Waltham, Massachusetts 02453
}

An animal's survival depends on finding food and the memory of food and contexts are often linked. Given that the hippocampus is required for spatial and contextual memory, it is reasonable to expect related coding of space and food stimuli in hippocampal neurons. However, relatively little is known about how the hippocampus responds to tastes, the most central sensory property of food. In this study, we examined the taste-evoked responses and spatial firing properties of single units in the dorsal CA1 hippocampal region as male rats received a battery of taste stimuli differing in both chemical composition and palatability within a specific spatial context. We identified a subset of hippocampal neurons that responded to tastes, some of which were place cells. These taste and place responses had a distinct interaction: taste-responsive cells tended to have less spatially specific firing fields and place cells only responded to tastes delivered inside their place field. Like neurons in the amygdala and lateral hypothalamus, hippocampal neurons discriminated between tastes predominantly on the basis of palatability, with taste selectivity emerging concurrently with palatability-relatedness; these responses did not reflect movement or arousal. However, hippocampal taste responses emerged several hundred milliseconds later than responses in other parts of the taste system, suggesting that the hippocampus does not influence real-time taste decisions, instead associating the hedonic value of tastes with a particular context. This incorporation of taste responses into existing hippocampal maps could be one way that animals use past experience to locate food sources.

Key words: chemosensation; hippocampus; place cells; taste

\section{Significance Statement}

Finding food is essential for animals' survival and taste and context memory are often linked. Although hippocampal responses to space and contexts have been well characterized, little is known about how the hippocampus responds to tastes. Here, we identified a subset of hippocampal neurons that discriminated between tastes based on palatability. Cells with stronger taste responses typically had weaker spatial responses and taste responses were confined to place cells' firing fields. Hippocampal taste responses emerged later than in other parts of the taste system, suggesting that the hippocampus does not influence taste decisions, but rather associates the hedonic value of tastes consumed within a particular context. This could be one way that animals use past experience to locate food sources.

\section{Introduction}

The hippocampus is essential for spatial learning and memory and is thought to provide a cognitive map of animals' experience. The central data for this view come from studies of place cells that

\footnotetext{
Received Sept. 25, 2018; revised Jan. 15, 2019; accepted Jan. 29, 2019.

Author contributions: L.E.H., D.B.K., and S.P.J. designed research; L.E.H., L.M.P., S.J.S., and E.R.M. performed research; L.E.H., L.M.P., S.J.S., E.R.M., D.B.K., and S.P.J. analyzed data; L.E.H., D.B.K., and S.P.J. wrote the paper.

This work was supported by the Alfred P. Sloan Foundation (Sloan Research Fellowship in Neuroscience to S.P.J.), the Whitehall Foundation (S.P.J.), and the National Institutes of Health (Grants R01 DC006666 and R01 DC007703 to D.B.K. and Training Grant T90 DA032435 to L.E.H.).

The authors declare no competing financial interests.

*D.B.K. and S.P.J. contributed equally to this work.

Correspondence should be addressed to either Donald B. Katz at dbkatz@brandeis.edu or Shantanu P. Jadhav at shantanu@brandeis.edu.

https://doi.org/10.1523/JNEUROSCI.2478-18.2019

Copyright $\odot 2019$ the authors
}

respond to specific locations as animals explore their environments (O'Keefe and Nadel, 1978; Moser et al., 2008).

Given that one of the most obvious uses for such a mental map is to aid in the finding of food, it is surprising how little is known about how the hippocampus processes taste, the most central sensory property of food. It is reasonable to expect that taste information reaches the hippocampus; although not traditionally considered to be part of the taste system, anatomical studies show that the hippocampus receives projections either directly or indirectly through the entorhinal cortex from several brain regions in which taste information is processed, including the gustatory cortex (GC), orbitofrontal cortex, and amygdala (Suzuki and Amaral, 1994; von Bohlen und Halbach and Albrecht, 2002). Functional imaging studies in humans also indicate that the hippocampal formation is active during taste ingestion and discrimination (Zald et al., 1998; Haase et al., 2009; Spetter et al., 2010) 
and rodent lesion studies suggest that the hippocampus plays a role in taste learning (Reilly et al., 1993; Stone et al., 2005; Chinnakkaruppan et al., 2014).

A great deal is known about taste responses in other parts of the taste system: in cortex, these responses evolve dynamically, reflecting taste presence, identity, and palatability in distinct epochs preceding the decision to consume or expel a given taste (Katz et al., 2001; Sadacca et al., 2012, 2016). However, it remains unclear whether or how hippocampal taste responses coexist and interact with representations of space. Although hippocampal neurons are known to respond to tastes in a context-dependent manner (Ho et al., 2011), no studies to date have directly measured single unit responses to tastes in the hippocampus alongside spatial firing properties, or examined the dynamics of these responses.

Hippocampal place cells are certainly capable of encoding nonspatial information such as odors (Wood et al., 1999), visual cues (Fried et al., 1997), textures (Shapiro et al., 1997), tones (Moita et al., 2003), and time (Kraus et al., 2013). Place cells typically respond to these stimuli by modulating their firing rate ("rate remapping"; Leutgeb et al., 2004; Allen et al., 2012) or firing location ("global remapping"; Leutgeb et al., 2005; Fyhn et al., 2007). A new cognitive map can also be formed based on the parameters of a behaviorally relevant nonspatial stimulus (Kraus et al., 2013; Aronov et al., 2017). The difficulty inherent in dissociating spatial from nonspatial influences in behaving rodents (O'Keefe, 1999), however, has led some researchers to propose that seeming responses to nonspatial stimuli may simply reflect arousal triggered by the onset of the stimulus rather than being true sensory responses (Shan et al., 2016). To establish that nonspatial responses are genuine, it is necessary to show that spatially tuned neurons can discriminate between sensory stimuli.

Here, we did just this by recording single-unit activity in the dorsal CA1 region of awake rats while exposing them to four taste solutions. We identified subsets of place cells and interneurons that discriminated between tastes based predominantly on palatability; this pattern was consistent with those observed in basolateral amygdala (BLA) (Fontanini et al., 2009) and lateral hypothalamus (LH) (Li et al., 2013), although hippocampal taste dynamics evolved much more slowly. Neurons classified as tasteresponsive place cells responded exclusively to tastes delivered within their place field and tended to have lower spatial selectivity than non-taste-responsive place cells. Together, these results establish that hippocampal responses to sensory stimuli do not simply reflect changes in arousal state and can encode sensory parameters relevant for behavior. Further, they suggest that hippocampal taste responses may be used to form value-related associations between tastes and contexts, which can facilitate using past experience to locate food sources.

\section{Materials and Methods}

\section{Animals and surgery}

Five adult (450-550 g) male Long-Evans rats (Charles River Laboratories, RRID:RGD_2308852) were used as subjects in this study. Rats were kept on a $12 \mathrm{~h}$ light/dark cycle, with all sessions taking place around the same time during the light period. All surgical and experimental procedures were conducted in accordance with the National Institutes of Health guidelines and approved by the Brandeis University Institutional Animal Care and Use Committee.

After several weeks of habituation to daily handling, animals were chronically implanted with a microdrive array consisting of 25-30 independently moveable tetrodes in the right dorsal hippocampal region CA1 (-3.6 mm AP, $2.2 \mathrm{~mm} \mathrm{ML}$ ) and an intra-oral cannula (IOC). Each IOC consisted of a polyethylene tube inserted beneath the temporalis muscle and terminating anterolateral to the first maxillary molar, allowing for the precise delivery of taste solutions onto the rat's tongue (Grill and Norgren, 1978; Travers and Norgren, 1986; Katz et al., 2001).

Following recovery from the implantation surgery ( $\sim 7-8 \mathrm{~d})$, rats were water deprived to $85-90 \%$ of their ad libitum weight to ensure taste consumption during the recording sessions. At $\sim 14 \mathrm{~d}$ after implantation, animals were habituated for at least $3 \mathrm{~d}$ to the behavioral chamber, sleep box, and the delivery of taste solutions through the IOC; place cells were expected to be stable after habituation (Thompson and Best, 1990; Agnihotri et al., 2004). Following habituation, we performed daily recording sessions in which rats were exposed to pseudorandomized sequences of four standard taste stimuli (see Fig. $1 A, B$ and "Passive taste administration paradigm" section). Following the conclusion of experiments, we made electrolytic lesions through each electrode tip to mark recording locations. Brains were sectioned into $50 \mu \mathrm{m}$ slices and stained with cresyl violet to confirm electrode placement in the hippocampal cell layer (see Fig. 1C).

\section{Passive taste administration paradigm}

Each recording session typically lasted between 2 and $3 \mathrm{~h}$ and consisted of three sessions in a $\sim 30 \times 35 \times 40 \mathrm{~cm}$ Plexiglas behavioral chamber (J. Green, Charles River Maker Lab, https://www.charlesrivermaker.com/) interleaved with four 15-20 min sleep sessions in a $\sim 30 \times 30 \times 40 \mathrm{~cm}$ black box (rest box). The first and last sessions in the behavioral chamber consisted of 15-20 min periods in which animals were habituated to the behavioral chamber in the absence of tastes. During the middle experimental session (depicted in Fig. $1 A$ ), rats received a pseudorandomized sequence of four standard taste stimuli [sweet: 4 mm saccharin (S); salty: $100 \mathrm{~mm}$ sodium chloride $(\mathrm{N})$; neutral: distilled water $(\mathrm{W})$; and bitter: 5 mM quinine hydrochloride $(\mathrm{Q})]$ that varied in hedonic value and fell within the range of concentrations typically used in other studies (3-20 mм saccharin, 10-300 mм sodium chloride, and 1-10 mм quinine; for review, see Frank and Brown, 2003; Kobayakawa et al., 2005; Accolla and Carleton, 2008; Geran and Travers, 2009; Rosen et al., 2010; Chen et al., 2011; MacDonald et al., 2012; Li and Lemon, 2015; Sadacca et al., 2016). Taste solutions were delivered directly onto the tongue in $\sim 40 \mu \mathrm{l}$ aliquots via four polyamide tubes inserted into the IOC, with a separate tube for each solution to prevent the mixing of tastes. Rats received 50 pseudorandomized repeats of each of the four taste stimuli, for a total of 200 taste deliveries. This number of deliveries allowed us to obtain sufficient numbers of in-field and out-of-field trials for each taste stimulus (see "In-field versus out-of-field analysis" section) before rats became satiated (Fontanini and Katz, 2005). This requisite number of trials per stimulus is much greater than what is typically used in studies of taste coding in awake rodents (10-30 trials; Katz et al., 2001; Li et al., 2013; Baez-Santiago et al., 2016; Li et al., 2016) and therefore necessitated limiting the number of stimuli (e.g., sour taste) required for these comparisons (Moita et al., 2003). The interval between taste deliveries was randomized to $13-17 \mathrm{~s}$, which is sufficiently long enough to prevent mixture effects or contamination by previous deliveries, even without rinses factored into the experimental paradigm because awake rats have previously been shown to engage in what amounts to a constant saliva rinse (Fontanini and Katz, 2006). The total amount of fluid delivered in each $\sim 50$ min taste administration period was $8 \mathrm{ml}$, after which animals had access to an additional 15-20 $\mathrm{ml}$ of water in their home cage.

\section{Electrophysiology}

Electrophysiological recordings were conducted using a SpikeGadgets system (Tang et al., 2017). Spikes were sampled at $30 \mathrm{kHz}$ and band-pass filtered between $600 \mathrm{~Hz}$ and $6 \mathrm{kHz}$. Local field potentials (LFPs) were sampled at $1.5 \mathrm{kHz}$ and band-pass filtered between 0.5 and $400 \mathrm{~Hz}$. During recording sessions, the animal's position and speed were recorded using an overhead monochrome CCD camera (30 fps) and tracked by LEDs affixed to the head stage.

Over $\sim 14 \mathrm{~d}$ following surgery, tetrodes were gradually advanced to the CA1 hippocampal cell layer, as identified by characteristic EEG patterns (sharp-wave ripples or SWRs; theta rhythm) as described previously (Jadhav et al., 2012, 2016; Tang et al., 2017). Tetrodes were readjusted after each day's recordings. Each animal had one hippocampal reference 
Table 1. Cell distribution across animals

\begin{tabular}{lrrrrrr}
\hline & \multicolumn{7}{l}{ CA1 cells } & \multicolumn{1}{l}{} \\
\cline { 2 - 7 } Animal & All & Pyr & Int & Taste responsive & Pyr & Int \\
\hline EM5 & 162 & 155 & 7 & 24 & 18 & 6 \\
LH36 & 41 & 39 & 2 & 7 & 5 & 2 \\
EM6 & 136 & 118 & 18 & 52 & 35 & 17 \\
LP1 & 91 & 79 & 12 & 11 & 6 & 5 \\
LH42 & 52 & 50 & 2 & 2 & 1 & 1 \\
Total & 482 & 441 & 41 & 96 & 65 & 31 \\
\hline
\end{tabular}

Summary of the number of taste-responsive and total CA1 cells recorded from each animal. Only the cells meeting the inclusion criteria (see Materials and Methods) are reported. Putative pyramidal cells (Pyr) and interneurons (Int) were identified on the basis of firing rate and spike width parameters. Neurons were classified as "taste-responsive" if they exhibited responses to taste presence, identity, and/or palatability.

tetrode in corpus callosum, which was also referenced to a ground screw installed in the skull overlying cerebellum.

Single units were isolated offline based on peak amplitude and principal components (Matclust, M.P. Karlsson). Only well isolated units with stable waveforms that fired at least 100 spikes per session were included in our analysis. As is typical for studies of hippocampal CA1 neurons (Fox and Ranck, 1981; Jadhav et al., 2016; Tang et al., 2017), putative interneurons were identified on the basis of firing rate $(>8.5 \mathrm{~Hz})$ and spike width $(<0.35 \mathrm{~ms})$ parameters (see Fig. $1 D)$. All other isolated units were classified as putative pyramidal cells. We emphasize that these distinctions are putative because definitive classifications of cell types cannot be determined from extracellular recordings alone. We isolated a total of 482 neurons from five rats conducted across nine experiments. Table 1 shows the distribution of cells across all five animals.

\section{SWR detection}

SWRs were detected as described previously (Jadhav et al., 2016; Tang et al., 2017) using the ripple-band (150-250 Hz) filtering of LFPs from multiple tetrodes. A Hilbert transform was used to determine the envelope of band-passed LFPs and events that exceeded a threshold (mean + $3 \mathrm{SD}$ ) were detected. SWR events were defined as the times around initially detected events when the envelope exceeded the mean. SWR periods were excluded from place field analysis, similar to previous studies (Jadhav et al., 2016; Tang et al., 2017).

\section{Palatability/preference data}

Palatability can be defined as the relative hedonic value of tastes; this characteristic is related, but not identical to, reward because palatability is a continuously varying property of taste that is easily manipulated by experience (Stone et al., 2005; Sadacca and Katz, 2011; Chinnakkaruppan et al., 2014). Taste palatability was assessed using a brief-access task (BAT) (Davis Rig Gustometer; Med Associates; for details, see Sadacca et al., 2016) in a separate cohort of adult male rats $(n=7)$ that underwent the same water restriction protocol as the rats used in the recording experiment. Consumption data were averaged across 2 testing days for each animal. The palatability rank order determined by the brief access test ( $>\mathrm{N}>\mathrm{W}>\mathrm{Q}$, see Fig. $6 \mathrm{C}$ ) matches what has been observed in numerous studies across a broad range of stimulus delivery methods and assessment techniques (Travers and Norgren, 1986; Breslin et al., 1992; Clarke and Ossenkopp, 1998; Fontanini and Katz, 2006; Sadacca et al., 2016).

\section{Experimental design and statistical analysis}

Spatial maps. To characterize the spatial firing properties of neurons, 2D occupancy-normalized firing rate maps (see Figs. 2, 4, 5) were made using $0.5 \mathrm{~cm}$ square bins and smoothed with a 2D Gaussian $(\sigma=3 \mathrm{~cm}$; Tang et al., 2017). Data from taste delivery ( $500 \mathrm{~ms}$ before to $2500 \mathrm{~ms}$ after) and SWR periods (see "SWR detection and modulation" section) were excluded from spatial map analysis. Peak rates for each cell were defined as the maximum firing rate across all spatial bins in the spatial map. Each cell's place field was defined as the largest cluster of neighboring spatial bins which had firing rates $\geq 20 \%$ of the peak rate; place field sizes were then calculated by multiplying the number of bins by the bin size (Brun et al., 2002). Unpaired $t$ tests were used to determine whether the mean firing field size differed significantly between taste-responsive and non-taste-responsive neurons of each cell type (see Fig. 4B; pyramidal cells: $n=65$ taste-responsive cells, $n=376$ non-taste-responsive cells; interneurons: $n=31$ taste-responsive cells, $n=10$ non-tasteresponsive cells).

Spatial specificity was determined by calculating the spatial information content, or amount of information that a single spike conveys about the animal's location in bits/spike using the following formula:

$$
\text { Spatial information content }=\sum P_{i}\left(R_{i} / R\right) \log _{2}\left(R_{i} / R\right)
$$

where $i$ is the bin number, $P_{\mathrm{i}}$ is the probability of occupancy for bin $i, R_{\mathrm{f}}$ is the mean firing rate for bin $i$, and $R$ is the overall mean firing rate of the cell (Skaggs et al., 1993).

Unpaired $t$ tests were used to determine whether the average spatial information content differed significantly between taste-responsive and non-taste-responsive neurons of each cell type (see Fig. $4 C$; pyramidal cells: $n=65$ taste-responsive cells, $n=376$ non-taste-responsive cells; interneurons: $n=31$ taste-responsive cells, $n=10$ non-taste-responsive cells).

In-field versus out-of-field analysis. To analyze how place cells responded to tastes delivered inside or outside of their place fields (see Fig. 5), only pyramidal cells exhibiting place-specific activity ( $n=395$ cells, defined as neurons with a peak rate that exceeded $1 \mathrm{~Hz}$ and spatial information content that exceeded 0.2 bits/spike, similar to Moita et al., 2003) were considered. Only place cells that contained at least 10 in-field and out-of-field deliveries of each taste were included in this in-field versus out-of-field analysis ( $n=26$ taste-responsive cells, $n=153$ non-tasteresponsive cells). A one-way ANOVA was used to assess differences between the mean in-field and out-of-field taste response magnitude (calculated using $\eta^{2}$, see "Taste selectivity" section) of taste-responsive and non-taste-responsive cells (see Fig. 5C). To ensure that comparable numbers of trials of each taste were delivered in-field, a one-way ANOVA was used to compare the mean number of in-field trials for each of the four tastes. An unpaired $t$ test was also used to compare the total number of in-field trials for taste-responsive and non-taste-responsive cells. To determine whether numbers of taste-responsive cells were underreported due to intertrial variability, we repeated our initial analyses of taste responsiveness (see "Taste response properties") using only in-field trials of place cells that met the in-field versus out-of-field analysis criteria $\left(n=179\right.$ cells). A $\chi^{2}$ test was used to evaluate whether this approach resulted in comparable numbers of presence-, identity-, and palatabilityresponsive cells.

Taste response properties. The pseudorandomized taste delivery paradigm used to characterize hippocampal responses to tastes is described above (see "Passive taste administration paradigm" section). Taste responses were characterized separately for each of the 482 isolated neurons, focusing on the $2500 \mathrm{~ms}$ of spiking activity following each taste delivery, a time period that includes previously identified taste-related responses, but precedes swallowing behaviors that remove tastes from the tongue and make neural responses difficult to interpret (Travers and Norgren, 1986; Katz et al., 2001). We analyzed a set of response properties ranging from general to specific, as have been identified in other parts of the taste system, including the GC (Katz et al., 2001; Sadacca et al., 2012), BLA (Fontanini et al., 2009; Piette et al., 2012), and LH (Li et al., 2013). Neurons were classified as "taste-responsive" (see Table 1 for summary) if they exhibited responses to taste presence, identity and/or palatability, as described below. All other neurons were classified as "non-taste-responsive." All statistical tests were performed in MATLAB (The MathWorks, RRID:SCR_001622) and evaluated at a level of $\alpha=$ 0.05 unless otherwise specified, with a Bonferroni correction applied for multiple comparisons.

First, nonspecific responses to taste presence (see Fig. $6 B$, light gray lines), which are common across all four types of taste delivery and thought to originate from somatosensory responses detecting a taste on the tongue, were determined by assessing whether evoked responses differed significantly from the baseline firing rate in responses collated across all 200 taste delivery trials (Katz et al., 2001). The significance of the difference was first established using the main effect for time in a two-way, mixed-effect ANOVA (taste [saccharin, $\mathrm{NaCl}$, water, quinine] $\times$ time [successive $500 \mathrm{~ms}$ bins of firing rate]). 
Next, responses to taste identity (see Fig. $6 B$, dark gray lines), in which at least one taste can be discriminated from the others, were assessed by determining whether the evoked responses to the four tastes (this time, collated across the 50 deliveries of each unique taste) differed from each other. We used a similar strategy as the one used to evaluate taste responsiveness, except in this case, the main effect for taste was considered.

Finally, responses to taste palatability (see Fig. 6D), which reflected the relative hedonic value of tastes as assessed in the BAT (see Fig. $6 C$ and "Palatability/preference data" section), were computed using a Spearman rank-order correlation $\left(r_{s}\right)$ between the evoked response and the palatability of the associated taste. Specifically, neurons with evoked firing rates that matched the ranking of taste preference ( $\mathrm{S}>$ $\mathrm{N}>\mathrm{W}>\mathrm{Q}$ ) in increasing or decreasing order had higher palatability index scores.

Population responses to tastes. For all tasteresponsive cells ( $n=96$, see "Taste response properties" for classification criteria), the mean evoked firing rate across trials was determined (Sadacca et al., 2012; Li et al., 2013; span, 0-2500 ms after taste delivery; step size, $50 \mathrm{~ms}$; window size, $500 \mathrm{~ms}$ ) and $Z$-scored separately for each taste (see Fig. $3 A$ ). Responses to all four tastes were sorted by the timing of their peak firing to saccharin.

Taste selectivity. The magnitude of taste responsiveness for each cell was quantified using $\eta^{2}$, a standard measure of ANOVA effect sizes that describes the proportion of variance in a dependent variable explained by each factor as follows:

$$
\eta^{2}=\mathrm{SS}_{(\text {factor })} / \mathrm{SS}_{(\text {total })},
$$

where SS is the sum of squares (Maier et al., 2015). In our analysis, we used the summed SS of the two main factors (time + taste) to calculate $\eta^{2}$. A $\chi^{2}$ goodness-of-fit test was used to determine whether $\eta^{2}$ values followed a normal distribution (see Fig. 3B). The Pearson correlation $(R)$ between spatial information content and $\eta^{2}$ was computed separately for place cells ( $n=395$ cells) and interneurons ( $n=41$ cells). As described above (see "In-field versus out-of-field analysis" section), a one-way ANOVA was used to assess differences in $\eta^{2}$ for the in-field and out-offield regions of taste-responsive ( $n=26$ cells) and non-taste-responsive $(n=153$ cells) place cells that fit our analysis criteria (see Fig. $5 C$ ).

Taste response dynamics. To determine the timing of presence-, identity-, and palatability-related responses in single neurons, Student's $t$ tests were conducted on successive time windows of each neuron's evoked response (Sadacca et al., 2012; Li et al., 2013; span, 0-2500 ms after taste delivery; step size, $50 \mathrm{~ms}$; window size, $500 \mathrm{~ms})$. To determine which taste(s) each of the identity- and palatability-responsive neurons $(n=40)$ preferentially responded to, the taste-evoked and baseline ( -500 to $0 \mathrm{~ms}$ before taste delivery) firing rates were compared using successive $t$ tests. A $\chi^{2}$ goodness-of-fit test was used to determine whether cells responded to one taste or to a particular number of tastes more than the others.

To analyze taste-related dynamics on a population-wide level, we constructed a histogram showing what percentage of the total 482 recorded neurons exhibited responses to taste presence, identity, and palatability at each time point following stimulus delivery (see Fig. 7A). To investigate the timing of different aspects of the taste experience present in hippocampal responses, we compared response onset times of presenceand identity-related firing (see Fig. $7 B$ ) as well as identity- and palatability-related firing (see Fig. 7C) in the subset of cells that exhibited both ( $n=19$ and 14 cells, respectively). Principal component analysis (PCA) (see Briggman et al., 2005; Harvey et al., 2012) was conducted on the pooled subset of 36 identity-responsive cells to determine when discriminative firing emerged in the population response following taste delivery, with significance assessed at the $\alpha=0.01$ level comparing the neural data with 10,000 instances of firing-rate-shuffled controls (see Fig. 7D).

Speed and position controls. To ensure that hippocampal responses to tastes were not actually caused by overall differences in movement following taste delivery or in response to different tastes, we used a one-way ANOVA to compare the average speed and distance traveled during the pre-taste versus the post-taste period ( $2.5 \mathrm{~s}$ before or after taste delivery, segmented into $500 \mathrm{~ms}$ bins with a $50 \mathrm{~ms}$ step size) across all tastes $(n=$ 1800 total trials across 9 sessions), as well as separately for each of the four tastes ( $n=450$ trials of each taste across 9 sessions). To confirm that tastes were delivered in different spatial locations in our paradigm, we used a one-way ANOVA to compare the mean number of taste trials in each spatial quadrant of the behavioral chamber.

\section{Results}

Hippocampal place cells and interneurons respond to tastes We examined taste responses in a total of 482 CA1 neurons recorded across 9 sessions in 5 rats (mean \pm SEM: $53.6 \pm 5.34$ neurons/session) that received a battery of 4 standard tastes via IOC (Fig. $1 A$ ). Tastes were delivered in random order and timing as rats explored the behavioral chamber, leading to a varied distribution of taste delivery locations, as exemplified in Figure $1 B$ (mean number of trials across sessions, quadrant 1: $46.4 \pm 6.57$ trials, quadrant 2: $55.2 \pm 14.58$ trials, quadrant 3: $64.2 \pm 12.16$ trials, quadrant 4: $34.1 \pm 5.34$ trials; one-way ANOVA, $p=0.23$ ). Histology confirmed that the majority of our tetrodes were located intermediately along the proximodistal axis of dorsal CA1 (Fig. 1C; Henriksen et al., 2010). Isolated single neurons were classified as either putative pyramidal cells $(91.5 \%, 441 / 482)$ or 
A

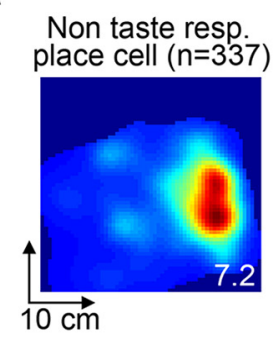

B

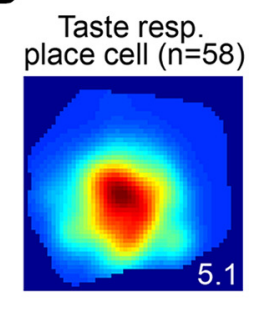

C Non taste resp.
interneuron $(n=10)$
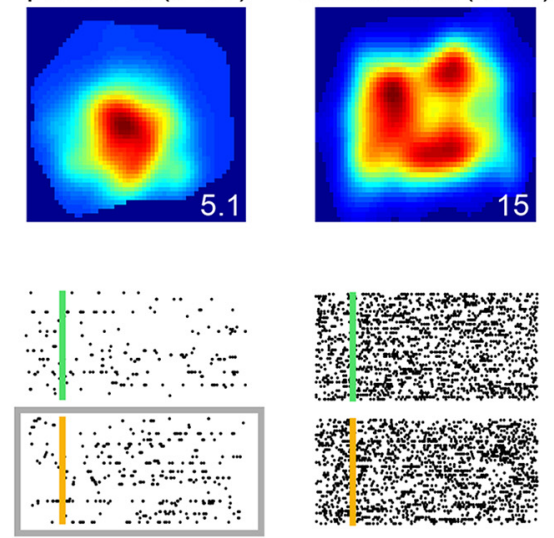

N

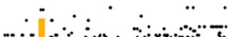

$\therefore \therefore \therefore \therefore-\therefore$

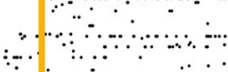

W

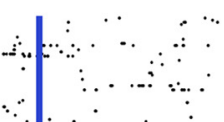
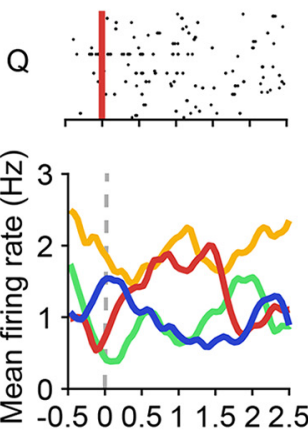
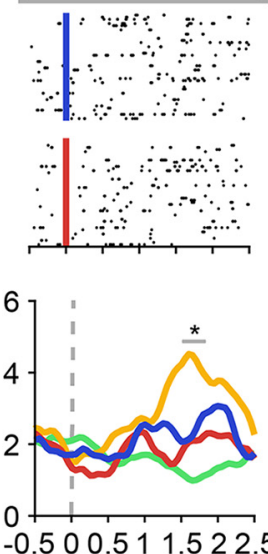
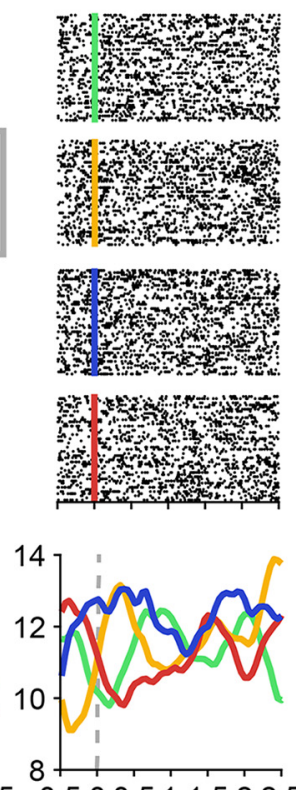

D
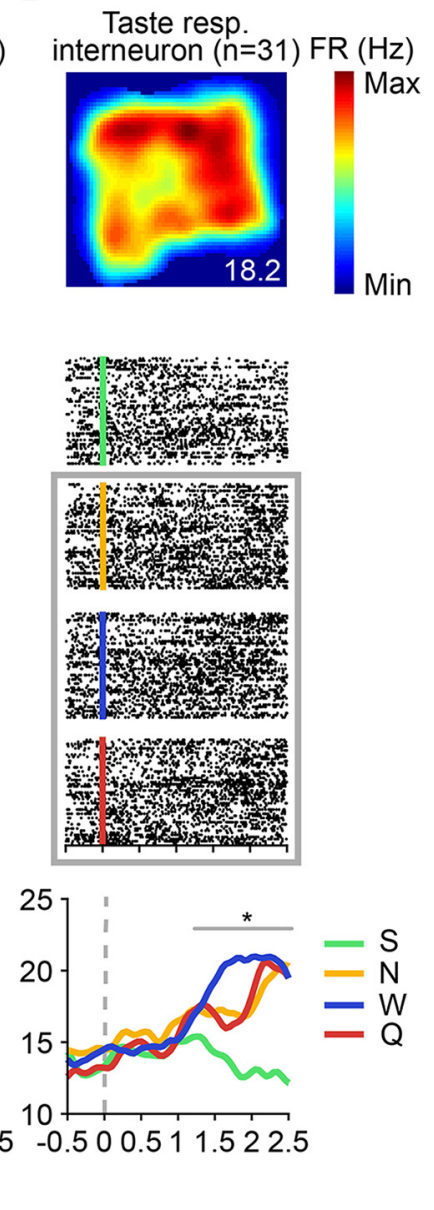

Figure 2. Subsets of hippocampal place cells and interneurons respond to tastes. $\boldsymbol{A}-\boldsymbol{D}$, Top, Example spatial firing maps of two place cells (left) and interneurons (right) calculated with taste delivery periods ( $500 \mathrm{~ms}$ before to $2500 \mathrm{~ms}$ after taste delivery) omitted from the analysis. Numbers on the bottom right of each plot denote peak spatial firing rate (FR) in $\mathrm{Hz}$. Middle, Raster plots of the cells in $\boldsymbol{A}-\boldsymbol{D}$ responding to each of the four tastes, with trials aligned to the time of taste delivery ( $\mathrm{S}$, green line, $4 \mathrm{~mm}$ saccharin; $\mathrm{N}$, yellow line, $100 \mathrm{~mm}$ sodium chloride; $\mathrm{W}$, blue line, distilled water; $Q$, red line, $5 \mathrm{~mm}$ quinine hydrochloride) and black dots indicating when spikes occurred during each trial. Light gray boxes indicate the taste(s) for which there was a significant evoked response $\left({ }^{*} p<0.05\right.$, $t$ tests on successive time windows). Bottom, Taste-evoked responses of each of the above neurons. Each colored trace represents the mean firing rate to one of the four tastes smoothed with a $1 D$ Gaussian filter $(\sigma=5 \mathrm{~ms})$. Light gray lines indicate the periods of significant taste responsiveness for the place cell in $\boldsymbol{B}$ and the interneuron in $\boldsymbol{D}$.

interneurons $(8.5 \%, 41 / 482)$ on the basis of baseline firing rates and action potential shape (Fig. 1D).

In total, 395 of the 441 pyramidal neurons were classified as place cells using standard analysis of the spatial specificity of firing rate responses (see Materials and Methods, Moita et al., 2003). The spatial firing maps of four representative place cells and interneurons (all of which were computed with taste delivery periods omitted from the analysis) are shown in the top row of Figure 2. As expected (O'Keefe and Dostrovsky, 1971; O'Keefe and Nadel, 1978), only the pyramidal cells had place fields (Fig. $2 A, B$ ); interneurons (Fig. $2 C, D$ ) typically exhibited high spontaneous firing rates regardless of the rat's position.

A cell was considered "taste-responsive" if significant firing rate modulations were evoked by taste presence, identity, and/or palatability (see Fig. 6 for more details). In total, 96/482 (19.9\%) cells were classified as taste-responsive, which is similar to the proportion reported in the only previous study to assess taste responses in individual hippocampal neurons (Ho et al., 2011). We found taste-responsive and taste-unresponsive units on tetrodes across the proximodistal axis of dorsal CA1 $(n=50 / 60$ tetrodes with taste-responsive units). Table 1 shows the distribution of taste-responsive cells across animals.
The raster plots and peristimulus time histograms (PSTHs) for an example taste-responsive place cell and interneuron are depicted in Figure 2, $B$ and $D$. The place cell in Figure $2 B$ responded to $\mathrm{NaCl}$ from $1550-1750 \mathrm{~ms}$ following taste delivery, whereas the interneuron in Figure $2 \mathrm{D}$ responded to $\mathrm{NaCl}$, water, and quinine from 1200-2500 ms following taste delivery (light gray lines). In contrast, the raster plots and PSTHs for non-tasteresponsive cells (Fig. 2A,C) showed no differences in evoked activity from baseline or between tastes.

The $Z$-scored firing rates (Fig. $3 A$ ) reveal the diversity of taste responses within the population of taste-responsive cells $(n=96$ cells). When $Z$-scored firing rates are ordered by the timing of each cell's peak excitatory response to saccharin (Fig. $3 A, S$ ), these responses tile the entirety of the taste delivery period. The breakdown of this sequence for $\mathrm{NaCl}$ (Fig. $3 A, N$ ), water (Fig. $3 A, W$ ), and quinine (Fig. $3 A, Q$ ) when the same cell order is conserved illustrates that taste-responsive cells respond preferentially and dynamically to different tastes. Figure $3 B$ reveals that the distribution of taste response magnitudes as quantified by $\eta^{2}$, a standard measure of ANOVA effect size (Maier et al., 2015) does not follow a normal distribution (number of histogram bins $=50$, bin width $=2 \mathrm{e}-04 ; \chi^{2}$ goodness-of-fit test, $\chi^{2}=57.5, p=3.3 \mathrm{e}-$ 
A

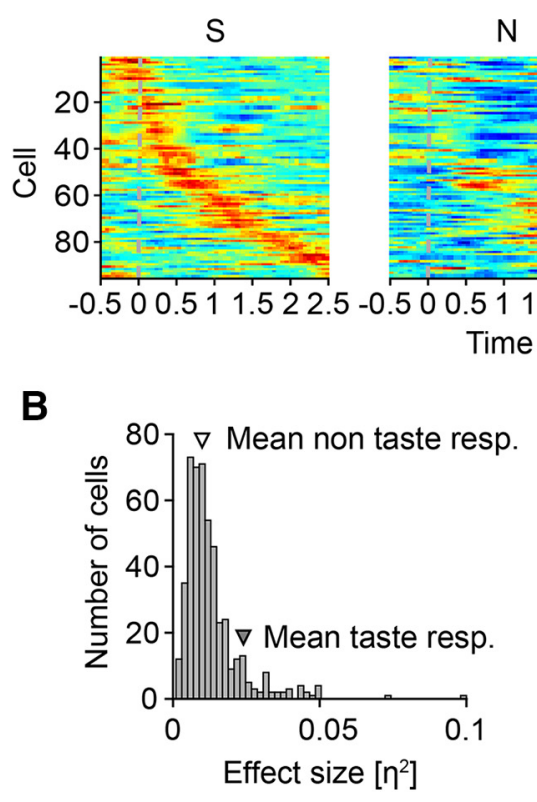

$\mathrm{N}$
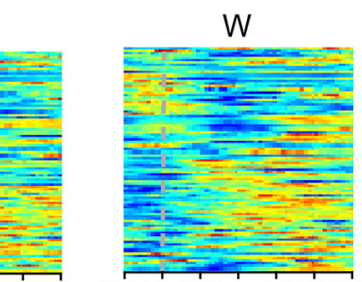

050151152

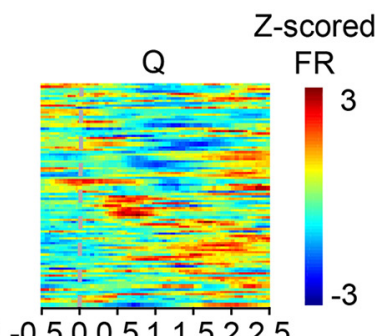

$5-0.500 .511 .522 .5$

(s)

. 
A

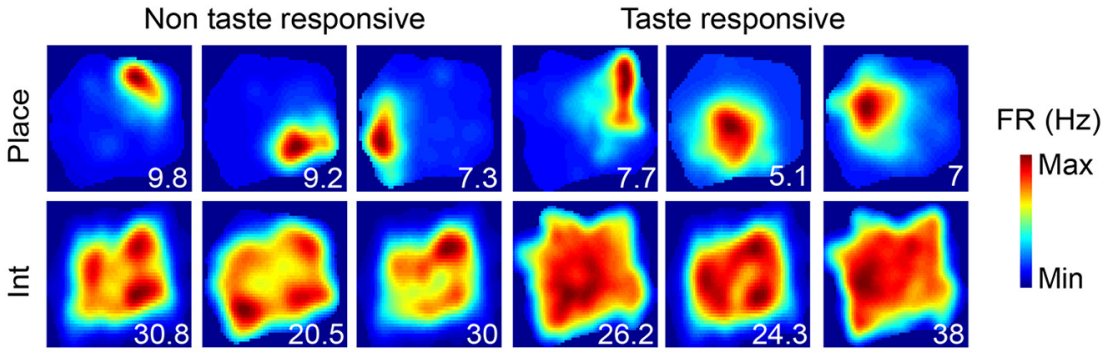

B

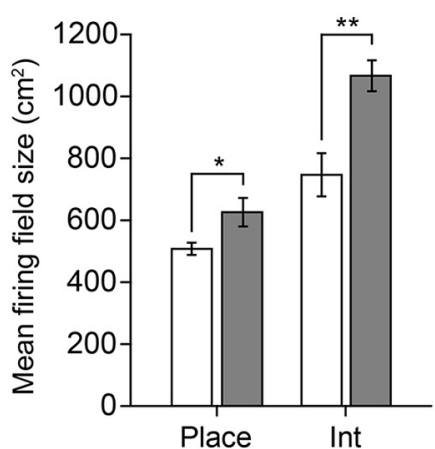

C

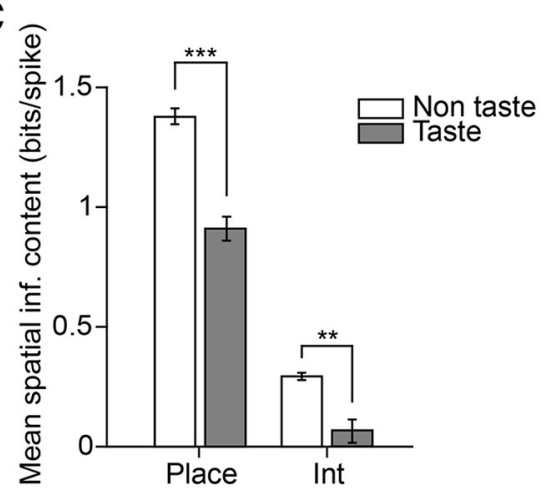

Figure 4. Taste-responsive hippocampal neurons exhibit weaker spatial selectivity than non-taste-responsive hippocampal neurons. $\boldsymbol{A}$, Example spatial firing maps of 12 non-taste-responsive (left) and taste-responsive (right) place cells (Place, top row) and interneurons (Int, bottom row). Note that taste-responsive cells tend to exhibit more diffuse spatial firing. All firing maps were computed with taste delivery periods ( 500 ms before to $2500 \mathrm{~ms}$ after taste delivery) omitted from the analysis. Numbers on the bottom right of each plot denote peak spatial firing rate (FR) in $\mathrm{Hz}$. B, Mean firing field size for non-taste-responsive (white bars) and taste-responsive (gray bars) place cells and interneurons. For each cell type, taste-responsive neurons had larger firing fields than non-taste-responsive neurons (place cells: $n=337$ non-taste-responsive cells, $n=58$ taste-responsive cells; unpaired $t$ test, ${ }^{*} p=0.021$; interneurons: $n=10$ non-taste-responsive cells, $n=31$ taste-responsive cells; unpaired $t$ test, ${ }^{* *} p=0.002$ ). $\boldsymbol{C}$, Mean spatial information content for non-taste-responsive (white bars) and taste-responsive (gray bars) place cells and interneurons. Within each cell type, taste-responsive neurons had a lower spatial information content than non-taste-responsive neurons (place cells, unpaired $t$ test, ${ }^{* * *} p=1.03 \mathrm{e}-06$; interneurons, unpaired $t$ test, ${ }^{* *} p=0.0027$ ).

$746.8 \pm 69.7 \mathrm{~cm}^{2}$; unpaired $t$ test, $p=0.002$; mean spatial information content, taste-responsive interneurons: $0.065 \pm 0.040$ bits/spike, non-taste-responsive interneurons: $0.29 \pm 0.015$ bits/ spike; unpaired $t$ test, $p=0.0027)$. There was a negative correlation between the spatial information content and magnitude of taste responsiveness $\left(\eta^{2}\right)$ within each cell type (place cells: Pearson correlation, $r=-0.18, p=3.27 \mathrm{e}-04$; interneurons: Pearson correlation, $r=-0.58, p=5.95 \mathrm{e}-05$ ), confirming that hippocampal neurons that respond strongly to taste delivery tend to have more diffuse firing in space.

The above analysis implies that, although place cells tended to exhibit fewer and lower-magnitude taste responses than interneurons, a subset of place cells exhibited taste-specific firing ( $n=58 / 395$ cells; example in Fig. $2 B$ ). Therefore, it is important to ask how place and taste responses interact when an animal receives familiar tastes in a specific spatial context: can place cells acquire sensory responses regardless of location or are responses to tastes gated by spatial firing, as suggested for other sensory modalities (Moita et al., 2003; Shan et al., 2016)? To investigate this question, we compared the specificity of taste responses inside and outside of each place cell's firing field.

Only place cells ( $n=58$ taste-responsive cells, $n=337$ nontaste-responsive cells) were considered for in-field versus out-offield analysis. We defined a cell's place field as the largest number of adjacent spatial bins that had firing rates $\geq 20 \%$ of the peak firing rate (Brun et al., 2002). To ensure sufficient sampling of taste responses for statistical comparisons, only cells that contained at least 10 in-field and out-of-field trials of each taste stim- ulus were included in our analysis $(n=26$ taste-responsive cells, $n=153$ non-tasteresponsive cells). Taste response magnitude $\left(\eta^{2}\right)$ was then determined separately for trials taking place within and outside each cell's place field.

The top row of Figure 5 shows the spatial firing maps of representative tasteresponsive (Fig. 5A) and non-tasteresponsive (Fig. 5B) place cells, with in-field and out-of-field trials indicated in pink. The distribution of taste trials in these cells was representative of the entire population analyzed, with comparable numbers of taste trials delivered in-field (number of in-field trials, taste-responsive cells, saccharin (S): $25.1 \pm 1.5$ trials, $\mathrm{NaCl}(\mathrm{N}): 25.5 \pm 1.5$ trials, water $(\mathrm{W})$ : $24.4 \pm 1.4$ trials, quinine $(\mathrm{Q}): 24.8 \pm 1.5$ trials; one-way ANOVA, $p=0.96$; number of in-field trials, non-taste-responsive cells, saccharin: $23.4 \pm 0.7$ trials, $\mathrm{NaCl}$ : $24.1 \pm 0.7$ trials, water: $23.3 \pm 0.7$ trials, quinine: $23.8 \pm 0.7$ trials; one-way ANOVA, $p=0.89$ ). The total number of in-field trials was also comparable across groups (number of in-field trials, tasteresponsive cells: $99.7 \pm 5.7$ trials, nontaste-responsive cells: $94.6 \pm 2.7$ trials; unpaired $t$ test, $p=0.46)$. Repeating our initial analyses of taste responsiveness using only the in-field trials of units that met our analysis criteria ( $n=179$ cells) resulted in comparable numbers of tasteresponsive cells ( $n=17$ cells using in-field trials, $n=26$ cells using all trials; $\chi^{2}$ test, $\chi^{2}=1.69, p=0.19$ ), indicating that the total number of taste-responsive neurons was not underestimated due to intertrial variability and cells previously classified as non-taste-responsive did not typically contain any regions of taste responsiveness, either in-field or out-of-field (see example in Fig. 5B).

For the taste-responsive cell (Fig. $5 A$ ), virtually all responses occurred within the cell's place field (Fig. $5 A$, left), with very little taste-evoked firing out of field (Fig. $5 A$, right). Conversely, no taste-evoked responses were observed in-field or out-of-field for the non-taste-responsive cell (Fig. 5B). This trend was representative of the entire population of place cells (Fig. $5 C$ ): the in-field region of taste-responsive cells had a higher mean $\eta^{2}$ value than the out-of-field region or either region of non-taste-responsive cells (mean $\eta^{2}$ values, taste-responsive cells, in-field: $0.036 \pm$ 0.0042; taste-responsive cells, out-of-field: $0.023 \pm 0.0027$; nontaste-responsive cells, in-field: $0.025 \pm 0.0013$; non-tasteresponsive cells, out-of-field: $0.0208 \pm 0.0011$; 1-way ANOVA, $p=3 \mathrm{e}-05)$. Together, these results indicate that hippocampal taste responses are gated by the spatial firing properties of place cells, a finding that is consistent with previous studies investigating tone-evoked sensory responses during auditory fear conditioning (Moita et al., 2003; Shan et al., 2016).

Hippocampal taste-specific responses reflect taste palatability at a relatively long delay

Previous work has shown that taste-specific firing in GC neurons evolves through three stages: following an initial, nonspecific re- 
A

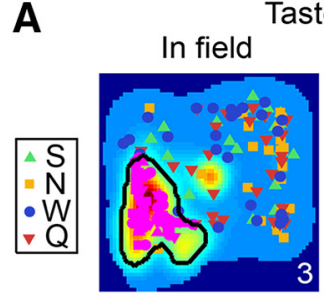

$\mathrm{S} \quad \cdots$

$\mathrm{N}=\left[\begin{array}{ll}\cdots \\ \cdots\end{array}\right.$

W
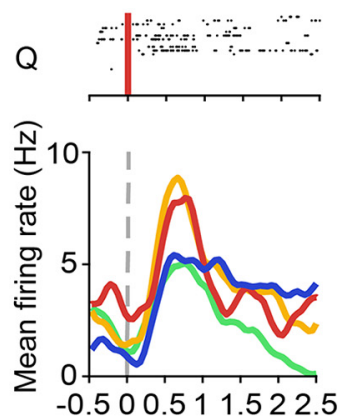
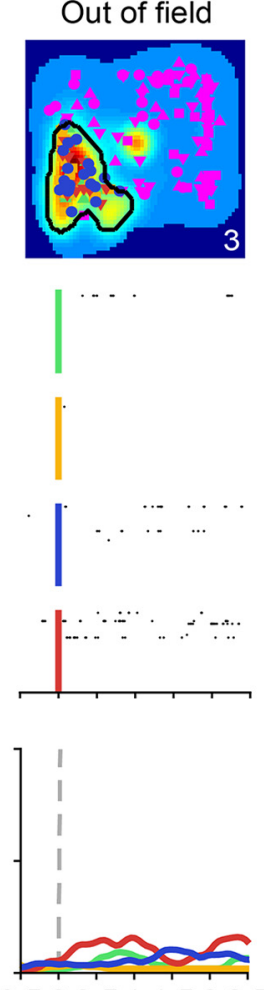

Time from taste delivery (s)
B
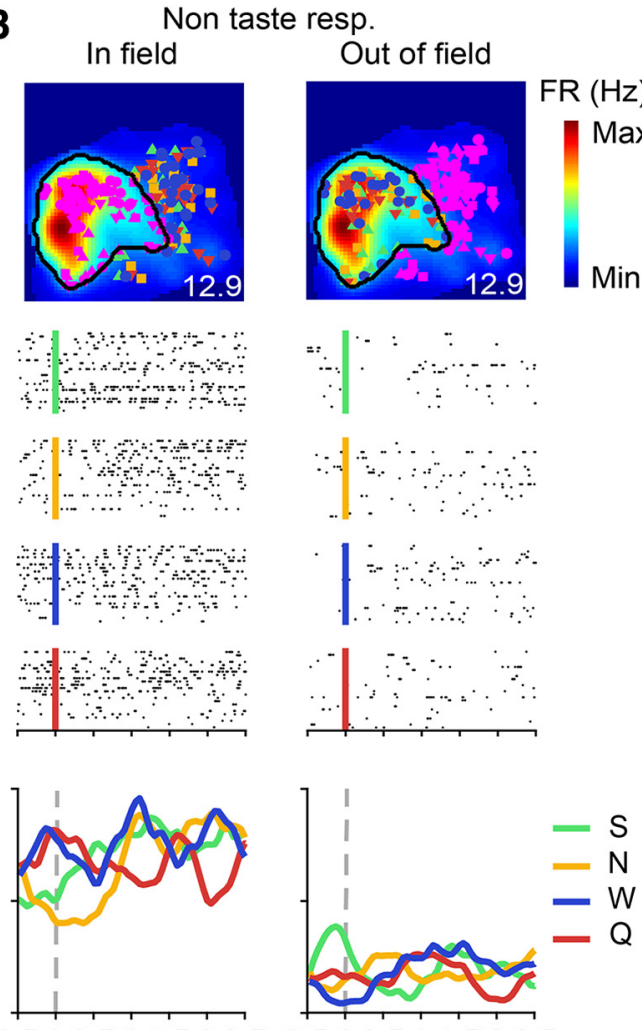

C

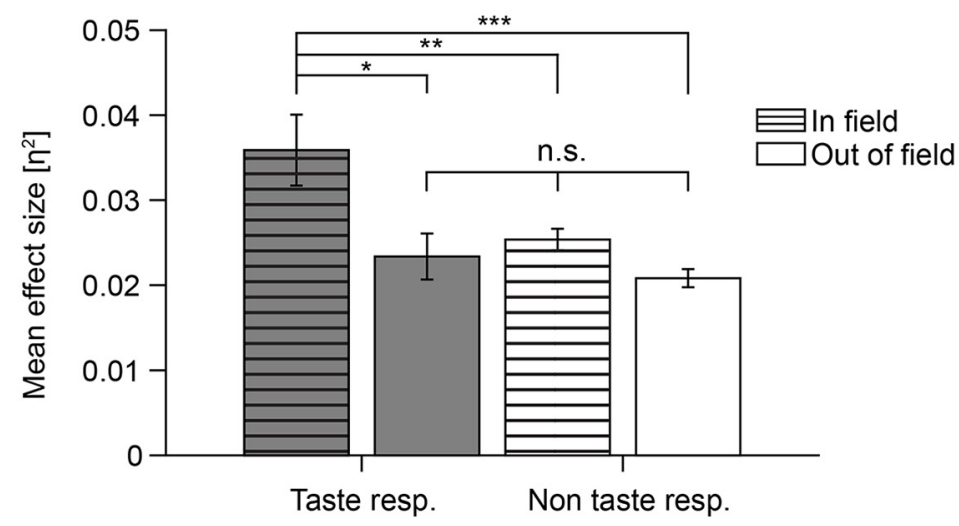

Figure 5. Place cells respond to tastes delivered within their place field. $\boldsymbol{A}, \boldsymbol{B}$, Example in-field and out-of-field responses for a taste-responsive $(\boldsymbol{A})$ and non-taste-responsive ( $\boldsymbol{B})$ place cell. Top panels show the spatial firing maps for each cell, with place field boundaries (defined as largest cluster of neighboring spatial bins which had firing rates $\geq 20 \%$ of the peak rate) indicated by black lines. The colored symbols represent locations of individual taste deliveries (green: $\mathrm{S}, 4 \mathrm{~mm}$ saccharin; yellow: $\mathrm{N}, 100 \mathrm{~mm}$ sodium chloride; blue: $\mathrm{W}$, distilled water; red: $\mathrm{Q}, 5 \mathrm{~mm}$ quinine hydrochloride) with either in-field (left) or out-of-field (right) trials highlighted in pink. All firing maps were computed with taste delivery periods ( $500 \mathrm{~ms}$ before to $2500 \mathrm{~ms}$ after taste delivery) omitted from the analysis. Numbers on the bottom right of each plot denote peak spatial firing rate (FR) in Hz. Middle panels depict raster plots of each cell's in-field (left) and out-of-field (right) responses to each of the four tastes. Black dots indicate spike times during each individual trial aligned to the time of taste delivery ( $\mathrm{S}$, green line, $4 \mathrm{~mm}$ saccharin; $\mathrm{N}$, yellow line, $100 \mathrm{~mm}$ sodium chloride; W, blue line, distilled water; $Q$, red line, 5 mm quinine hydrochloride). Bottom panels show the evoked responses to taste deliveries taking place in-field and out-of-field for each cell. Each colored trace represents the mean firing rate to one of the four tastes, smoothed with a 1D Gaussian filter $(\sigma=5 \mathrm{~ms})$. Note that taste responses are only found within the taste-responsive cell's place field (left panel of $A$ ). C, Mean magnitude of taste responsiveness $\left(\eta^{2}\right)$ for the in-field and out-of-field regions of taste-responsive and non-taste-responsive place cells that fit our criteria ( $\geq 10$ trials in- and out-of-field; $n=26$ taste-responsive cells, $n=153$ non-taste-responsive cells). The mean $\eta^{2}$ value for the in-field region of taste-responsive place cells (striped gray bar) was higher than that of the in-field region of non-taste-responsive cells (striped white bar), the out-of-field region of taste-responsive cells (gray bar), or the out-of-field region of non-taste-responsive (white bar) cells (1-way ANOVA, ${ }_{* * *} p=3 \mathrm{e}-05$ ), indicating that place cells only respond to tastes delivered within their place field.

sponse to taste presence, a discriminative response conveys information about taste identity starting at $\sim 200 \mathrm{~ms}$ after stimulus administration; after $\sim 500 \mathrm{~ms}$, responses then change to reflect palatability, specifically anticipating an animal's decision to consume or expel a particular taste between 600 and $1600 \mathrm{~ms}$ after taste delivery (Katz et al., 2001; Piette et al., 2012; Sadacca et al.,
2012, 2016; Maier and Katz, 2013; Li et al., 2016). Brainstem taste responses in the parabrachial nucleus $(\mathrm{PbN})$ are similarly organized (Baez-Santiago et al., 2016). However, other nodes of the taste CNS, such as the BLA and LH, appear instead to respond primarily and immediately to the hedonic value of tastes regardless of identity (Nishijo et al., 1998; Fontanini et al., 2009; Li et al., 
A

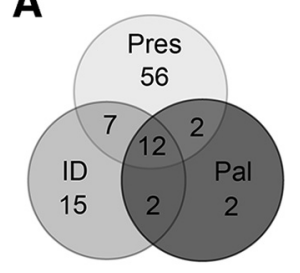

C

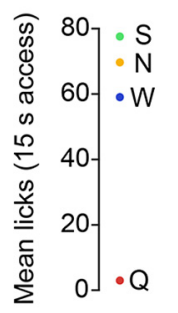

B

$S$

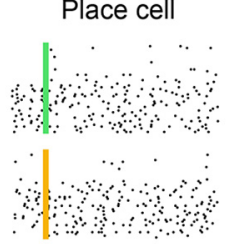

W
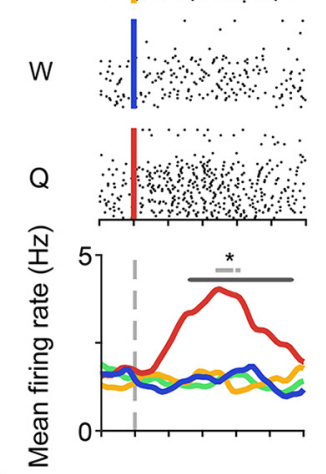

D

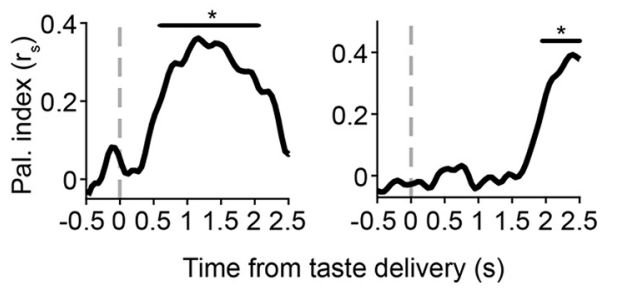

Interneuron
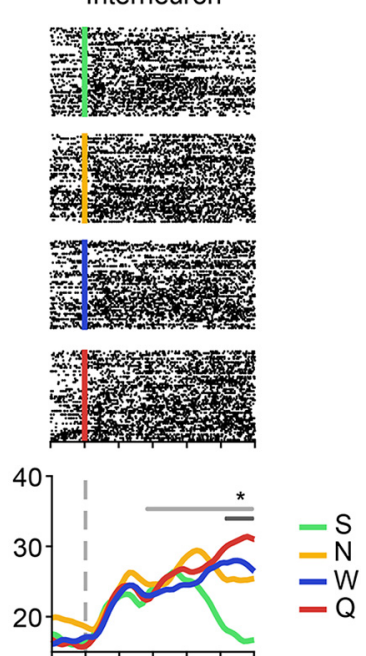
$-S$
$-N$
$-W$
$-Q$

Figure 6. Example hippocampal responses to different elements of the taste experience. $A$, Summary of the number of tasteresponsive cells ( $n=96 / 482$ cells) that responded to taste presence (Pres, $n=77$ cells), identity (ID, $n=36$ cells), and/or palatability (Pal, $n=18$ cells). $\boldsymbol{B}$, Example raster plots and PSTHs from a taste-responsive place cell (left) and interneuron (right). Black dots in the raster plots (top four panels) represent spike times during each trial, aligned to taste delivery time ( $S$, green line, $4 \mathrm{~mm}$ saccharin; $N$, yellow line, 100 mм sodium chloride; W, blue line, distilled water; $Q$, red line, 5 mм quinine hydrochloride). Each colored trace in the PSTHs (bottom) represents the mean firing rate to one of the four tastes, smoothed with a 1D Gaussian filter $(\sigma=5 \mathrm{~ms})$. Light gray lines indicate periods of significant responses to taste presence, whereas dark gray lines indicate periods of significant responses to taste identity ( ${ }^{*} p<0.05, t$ tests on successive time windows). C, Relative palatability of the four taste stimuli as determined by a BAT. Palatability rank is determined by the average number of licks per $15 \mathrm{~s}$ of exposure to the given taste. $\boldsymbol{D}$, Rank-order correlation $\left(r_{s}\right)$ between the taste-evoked firing rates and palatability rank $(S>N>W>0)$ for the place cell (left) and interneuron (right) depicted in $\boldsymbol{B}$. Black lines indicate periods of significant palatability relatedness $\left({ }^{*} p<0.05\right.$, $t$ tests on successive time windows). Note the similarity between the timing of palatability- and identity-related responses (dark gray lines in $\boldsymbol{B})$.

2013). To determine which components are present in hippocampal taste responses (and when), we performed analyses similar to those brought to bear on firing in these other structures.

Many hippocampal neurons responded nonspecifically to taste presence, providing information that could allow for the detection of tastants on the tongue (Fig. 6A). In a subset of these cells, responses were more discriminative, providing information about taste identity and/or palatability. Two such neurons are shown in Figure 6B, one of which (place cell, left) rapidly developed a response primarily to quinine and one of which (interneuron, right) produced a longer-latency response that differentiated each of the four tastes that notably involved a sudden change of firing rate to saccharin. As illustrated previously (Fig. $3 A$ ), we observed a relatively uniform distribution among taste-discriminative cells $(n=40)$ of which taste(s) cells responded to (number of cells with significant evoked responses to saccharin: 20 cells, $\mathrm{NaCl}$ : 29 cells, water: 26 cells, quinine: 25 cells; $\chi^{2}$ goodnessof-fit test, $\left.\chi^{2}=1.7, p=0.64\right)$. Similar to the interneuron shown in Figure $6 B$, most taste-discriminative cells responded to more than one taste (number of cells responding to one taste: 11 cells, two tastes: 4 cells, three tastes: 19 cells, four tastes: 6 cells; $\chi^{2}$ goodness-of-fit test, $\chi^{2}=13.4, p=0.0038$ ).

Closer examination revealed that the patterning of both responses in Figure $6 B$ reflected taste palatability across the entirety of the periods of taste-specific firing (Fig. 6D). Responses to taste palatability were assessed, as is typical in studies of taste temporal coding ( $\mathrm{Li}$ et al., 2013; Baez-Santiago et al., 2016; Sadacca et al., 2016), in terms of the correlation between neuronal firing rates and the order of taste preference, which was assayed in a brief access task (Li et al., 2013; Monk et al., 2014; Sadacca et al., 2016) run on a separate cohort of experimental rats (Fig. 6C). The observed order of taste preference $(\mathrm{S}>\mathrm{N}>\mathrm{W}>\mathrm{Q})$ shown in Figure $6 \mathrm{C}$ is consistent with that observed across a broad range of stimulus delivery methods and assessment techniques (Travers and Norgren, 1986; Breslin et al., 1992; Clarke and Ossenkopp, 1998; Fontanini and Katz, 2006; Sadacca et al., 2016).

Figure $6 D$ reveals that palatability correlations for the example neurons shown in Figure $6 B$ developed as the tastespecific responses themselves developed: the place cell's responses (Fig. $6 B$, left) were significantly correlated with taste palatability between 600 and $2100 \mathrm{~ms}$ (Fig. 6D, left), whereas the interneuron's responses (Fig. $6 B$, right) were palatability related between 2000 and $2500 \mathrm{~ms}$ (Fig. $6 D$, right; compare these periods with the dark gray line in Fig. $6 B$, which marks the period of significantly tastespecific firing).

Again, the examples shown in Figure 6 suggest that, like responses observed in limbic structures (Fontanini et al., 2009; Li et al., 2013; i.e., BLA and LH) but unlike those in the main taste axis (Sadacca et al., 2012; Baez-Santiago et al., 2016; i.e., GC and PbN), hippocampal taste responses do not go through a period of "pure" taste specificity before becoming palatability related. These appearances were borne out in an analysis of the entire neural dataset. Figure $7 A$ shows, similar to what has been observed in all other parts of the taste system (Katz et al., 2001; Fontanini et al., 2009; Sadacca et al., 2012; Li et al., 2013; Baez-Santiago et al., 2016), that totally nonspecific responses to taste presence emerged first in hippocampus, followed by responses to taste identity and palatability. However, both taste specificity and palatability relatedness appeared in hippocampal taste responses at similarly long latencies (average onset, presence: $1032.5 \pm 55.73 \mathrm{~ms}$; identity: $1443.1 \pm 108.07 \mathrm{~ms}$; palatability: $1797.2 \pm 118.51 \mathrm{~ms})$.

Direct within-neuron comparisons strongly supported the group analysis. Presence-related responses reliably arose before identity-related responses in cells that responded to both properties ( $n=19$ cells, paired $t$ test, $p=7.6 \mathrm{e}-05)$, as also evidenced by the cloud of points above the unity line (Fig. $7 B$; regression slope: $0.079, p=0.79$ ). A plot of the onset latency of identity- and palatability-related responses in cells where both properties were present, meanwhile, revealed tight clustering around the unity line (Fig. $7 C ; n=14$ cells; regression slope: $0.92, p=8.7 \mathrm{e}-06$ ) 
A

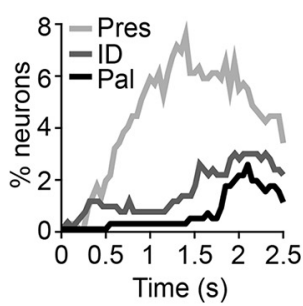

B

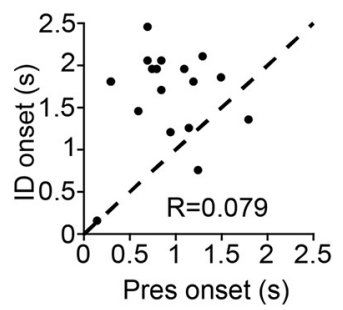

C

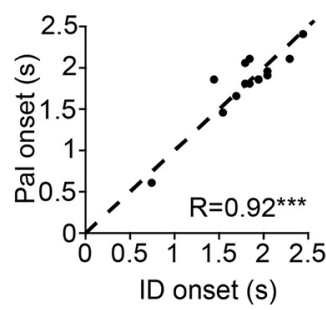

D

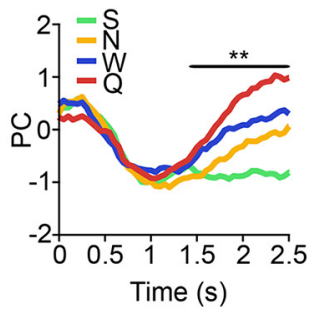

Figure 7. Hippocampal neurons discriminate between tastes based on palatability. $\boldsymbol{A}$, Histogram showing the percentage of hippocampal neurons that responded significantly to taste presence (Pres, light gray line), identity (ID, dark gray line), or palatability (Pal, black line) at each time point relative to taste delivery. Nonspecific responses to taste presence emerged before responses to taste identity or palatability, which occurred at similarly long latencies. $\boldsymbol{B}$, For the 19 cells that responded significantly to taste presence and identity, the onset of the identity-related response ( $y$-axis) is plotted against the onset of the presence-related response ( $x$-axis). Similar to what is seen in $\boldsymbol{A}$, single-neuron responses to taste presence typically preceded responses to taste identity, as evidenced by the cloud of points above the unity line (black dashed line). $C$, For the 14 cells that responded significantly to taste identity and palatability, the onset of the palatability-related response $(y$-axis) is plotted against the onset of the identity-related response ( $x$-axis). Responses to identity and palatability tended to emerge simultaneously in single units, as evidenced by tight clustering around the unity line (regression slope $=0.92,{ }^{* * *} p=8.68 \mathrm{e}-06$ ). D, PCA of identity-responsive cells ( $n=36$ cells). Each colored line depicts the PC of pooled responses to each of the four tastants (green: S, 4 mm saccharin; yellow: N, 100 mm sodium chloride; blue: W, distilled water; red: Q, 5 mm quinine hydrochloride) over time. Palatability-relatedness emerges at the same time as taste selectivity, as shown by significant encoding of palatability rank ( $\mathrm{S}>\mathrm{N}>\mathrm{W}>0$, in reverse order here; ${ }^{* *} p<0.01$, comparison with firing-rate-shuffled controls) by the $\mathrm{PC}$ s starting at $\sim 1.4 \mathrm{~s}$ after stimulus delivery (black line).

with no significant differences between onset times (paired $t$ test, $p=0.83$ ), suggesting that these properties arose simultaneously in single-unit responses.

Finally, we performed PCA by pooling responses of identityresponsive cells ( $n=36$ cells) to visualize the onset of tastespecific firing in the population as a whole. This analysis suggests that tastes are discriminated based on palatability, as shown by significant encoding of palatability rank (here, in reverse order as shown in Fig. $6 C$ ) by the principal components starting at $\sim 1.4 \mathrm{~s}$ after stimulus delivery (Fig. 7D). It is important to note that this analysis is not representative of every cell: we identified a small but significant contingent of exclusively identity-coding neurons ( $n=15 / 96$ taste-responsive cells; see Fig. $2 B$ for example). It is worth noting, however, that even many of the neurons that responded strongly and specifically to single tastes did so to either the most rewarding or aversive tastants in our battery (see Fig. $6 B$ for examples).

We therefore conclude that hippocampal "taste codes" do not contain the purely identity-related component found in gustatory brainstem and cortex; rather, taste selectivity emerges at the same time as palatability-relatedness and, as a whole, the tastereactive hippocampal population delivers information on palatability without a prior epoch of less structured taste-specificity. In this regard, hippocampal responses are similar to those observed in other noncortical parts of the taste system, such as the BLA (Fontanini et al., 2009) and LH (Li et al., 2013); notably, however, palatability coding appears in hippocampus much later than it appears in these other limbic structures, a difference that likely has strong implications for the potential roles of the hippocampus in taste (see Discussion below).

\section{Discussion}

Our findings suggest that place and taste responses can coexist within the same hippocampal neurons and that these response modalities influence one another. Taste-responsive cells tended to have less spatially specific firing fields (Figs. 2, 4). Conversely, place cells that responded to tastes did so in a spatially specific manner (Fig. 5), with responses only occurring within that cell's place field. Hippocampal neurons discriminated between tastes at relatively long latencies and predominantly on the basis of palatability (Figs. 6, 7), confirming that these responses can encode sensory parameters and do not simply reflect changes in animals' movement or attentive state, as has been suggested (O'Keefe, 1999; Shan et al., 2016). These results stand alongside similar studies of audition (Moita et al., 2003) and olfaction (Wood et al., 1999) and further show that spatially tuned hippocampal neurons can discriminate between behaviorally relevant sensory stimuli. Our observations add to an expanding view of the hippocampal cognitive map as a representation that encompasses both spatial and nonspatial aspects of an animal's environment (Shapiro et al., 1997; Eichenbaum et al., 1999; Wood et al., 1999; Moita et al., 2003; Kraus et al., 2013; Aronov et al., 2017).

In total, $\sim 20 \%$ of recorded hippocampal cells in our study were classified as taste-responsive (Fig. 2), which is comparable to the proportion reported in the only previous study to assess taste responses in individual hippocampal neurons (Ho et al., 2011). Our usage of IOCs for enhanced stimulus control allowed us to build upon Ho et al.'s (2011) findings uncovering new understanding of the structure, content, and dynamics of hippocampal taste responses. Similar to what is seen elsewhere in the taste system, including the GC (Katz et al., 2001), BLA (Fontanini et al., 2009), LH (Li et al., 2013), and PbN (Baez-Santiago et al., 2016), we observed larger-than-chance numbers of CA1 neurons that responded discriminatively to taste stimuli (Fig. 6A), with response specificity evolving over time (Fig. 7). This tastedistinctiveness, along with the history of taste research that has been conducted in rodents using IOCs, further underscores that hippocampal taste responses are truly gustatory and do not arise from stress or fear responses caused by the delivery of solutions via IOC (Travers and Norgren, 1986; Katz et al., 2001; Sadacca et al., 2016).

Unlike what has been observed in GC (Katz et al., 2001; Sadacca et al., 2016) and PbN (Baez-Santiago et al., 2016), we found little evidence of pure identity coding in the hippocampus in this passive administration paradigm. Instead, hippocampal neurons distinguish between tastes based on palatability (Fig. 7), similar to other taste system limbic structures such as the BLA (Fontanini et al., 2009) and LH (Li et al., 2013). However, palatability-related hippocampal coding emerged much later than in BLA or LH and likely after the time (although more direct measurements must be taken to ascertain this) that animals make decisions about palatability-related orofacial behaviors (Li et al., 2016; Sadacca et 
al., 2016). These results support the idea that the hippocampus does not contribute to an animal's decision to consume or expel a given taste. Rather, it responds to the hedonic value of tastes consumed within a particular context, forming associations between place and reward that may be relayed downstream via hippocampal projections to the ventral tegmental area and other neural reward centers (Lisman et al., 2011). This could serve as a means of relating place to taste in terms of its inherent reward value, allowing animals to use past experience to locate food sources.

Although spatial learning is indisputably considered to be a hippocampal-dependent process (Morris, 1984; Moser et al., 2008), the role of the hippocampus in nonspatial taste learning is less clearcut. Some forms of taste learning, such as social transmission of food preferences (Bunsey and Eichenbaum, 1995; Countryman et al., 2005), are considered to be hippocampal dependent; other paradigms (e.g., conditioned taste aversion) undergo variable effects after hippocampal lesions (Yamamoto et al., 1995; Stone et al., 2005; Chinnakkaruppan et al., 2014). Future studies in which individual neurons are recorded during taste learning, which have been informative when focused on other nodes of the taste system (Grossman et al., 2008; Lavi et al., 2018), may help to decipher how the hippocampus encodes tastes and contexts to guide future food choices.

Our study provides the first direct evidence that hippocampal taste responses are almost entirely gated by the neurons' spatial firing properties. More specifically, taste responses are more prevalent in interneurons than place cells (Fig. 2), associated with broader spatial responsiveness regardless of cell type (Fig. 4), and limited to cells' spatial firing fields (Fig. 5). Our finding that place cells only respond to tastes delivered within their place field is consistent with previous studies (Moita et al., 2003; Shan et al., 2016) indicating that taste responses can best be understood as a rate code overlaid on existing representations of space. Because place fields can be modulated by food reward (Dupret et al., 2010; Allen et al., 2012), it seems likely that taste responses could arise as a consequence of place cell remapping. However, we could not address this question in the current study because rats did not explore the behavioral chamber in the absence of tastes, making it difficult to calculate place fields. We specifically chose a smaller open-field environment for these experiments because it allowed adequate coverage of place fields as well as multiple taste stimuli, allowing us to study the real-time interaction between taste and place. Future studies that incorporate place-specific taste delivery in a larger or more structured environment, such as a linear track, will be able to explore whether taste experience can modify animals' hippocampal representation of environments through rate or global remapping, as has been shown for other sensory modalities (Moita et al., 2004; Fyhn et al., 2007; Zhang and ManahanVaughan, 2015).

Whatever the relationship between spatial and gustatory firing, more hippocampal interneurons-by their very nature, non-place cells_-responded to nonspatial stimuli than place cells (Fig. 2). This result is consistent with studies that measured hippocampal responses to auditory (Moita et al., 2003) or olfactory (Deshmukh and Bhalla, 2003) stimuli. This finding may reflect the intrinsic properties of each cell type: place cells have lower mean firing rates and rarely respond outside of their place field, whereas interneurons exhibit high firing rates regardless of location (Fig. 2), making it much easier to obtain statistical significance in the latter. Another (though not mutually exclusive) possibility is that interneurons could be influencing place cell activity. Although place cells' responses to space have been well characterized (O'Keefe and Nadel, 1978; Moser et al., 2008), recent work suggests that interneurons also contribute to hippocampal representations of space (Wilent and Nitz, 2007) and disinhibit place cell firing through location-specific decreases in activity (Hangya et al., 2010; Royer et al., 2012). Because interneurons' projections are primarily internal to the hippocampal network (Freund and Buzsáki, 1996; Kullmann, 2011), these responses may play a role in shaping activity within the network, such as place fields (Fig. 4) or location-specific responses to tastes (Fig. 5). However, how nonspatial information is transmitted within hippocampal microcircuits remains an open question, one that may be investigated in future studies by determining the effect of cell-type-specific inhibition on hippocampal taste responses.

There is strong evidence that the behavioral relevance of sensory stimuli within a task influences what proportion of hippocampal neurons respond to nonspatial cues. In our study, rats passively received tastes via IOC, a paradigm that requires no learning other than associating tastes with a context for the first time. The total proportion of taste-responsive neurons in our study ( $\sim 20 \%$, Fig. 2 ) is comparable to the proportion of toneresponsive cells (16\%) found by one study analyzing the auditory evoked responses of hippocampal neurons (Moita et al., 2003); however, this proportion increased to $52 \%$ following auditory fear conditioning. Similarly, $\sim 40 \%$ of hippocampal neurons exhibited nonspatial firing during an odor-guided non-match-tosample task that required working memory of spatial and nonspatial factors (Wood et al., 1999). More pronounced changes in hippocampal responsiveness are observed when reward contingencies are entirely dependent on discriminating between nonspatial cues, such as in one study where rats learned to manipulate a joystick to modulate a tone within a target frequency range (Aronov et al., 2017). During this task, $\sim 40 \%$ of hippocampal neurons responded to specific tone frequencies compared with only $2 \%$ during the passive playback of tones. In our study, $8.3 \%$ (40/482) of CA1 neurons discriminated between tastes (Fig. 6A), with an additional 11.6\% (56/482) of cells responding nonspecifically to taste presence. These results suggest that the hippocampus forms a flexible map of spatial and nonspatial stimuli based on current behavioral demands. For the case of taste, gustatory responses in spatially tuned hippocampal neurons may allow animals to form value-related associations between tastes and contexts, aiding in the finding of food. Future work will assess how taste experience affects this ongoing mental map.

\section{References}

Accolla R, Carleton A (2008) Internal body state influences topographical plasticity of sensory representations in the rat gustatory cortex. Proc Natl Acad Sci U S A 105:4010-4015.

Agnihotri NT, Hawkins RD, Kandel ER, Kentros C (2004) The long-term stability of new hippocampal place fields requires new protein synthesis. Proc Natl Acad Sci U S A 101:3656-3661.

Allen K, Rawlins JN, Bannerman DM, Csicsvari J (2012) Hippocampal place cells can encode multiple trial-dependent features through rate remapping. J Neurosci 32:14752-14766.

Aronov D, Nevers R, Tank DW (2017) Mapping of a nonspatial dimension by the hippocampal-entorhinal circuit. Nature 543:719-722.

Baez-Santiago MA, Reid EE, Moran A, Maier JX, Marrero-Garcia Y, Katz DB (2016) Dynamic taste responses of parabrachial pontine neurons in awake rats. J Neurophysiol 115:1314-1323.

Breslin PA, Spector AC, Grill HJ (1992) A quantitative comparison of taste reactivity behaviors to sucrose before and after lithium chloride pairings: a unidimensional account of palatability. Behav Neurosci 106:820-836.

Briggman KL, Abarbanel HD, Kristan WB Jr (2005) Optical imaging of neuronal populations during decision-making. Science 307:896-901. 
Brun VH, Otnass MK, Molden S, Steffenach HA, Witter MP, Moser MB, Moser EI (2002) Place cells and place recognition maintained by direct entorhinal-hippocampal circuitry. Science 296:2243-2246.

Bunsey M, Eichenbaum H (1995) Selective damage to the hippocampal region blocks long-term retention of a natural and nonspatial stimulusstimulus association. Hippocampus 5:546-556.

Chen X, Gabitto M, Peng Y, Ryba NJ, Zuker CS (2011) A gustotopic map of taste qualities in the mammalian brain. Science 333:1262-1266.

Chinnakkaruppan A, Wintzer ME, McHugh TJ, Rosenblum K (2014) Differential contribution of hippocampal subfields to components of associative taste learning. J Neurosci 34:11007-11015.

Clarke SN, Ossenkopp KP (1998) Taste reactivity responses in rats: influence of sex and the estrous cycle. Am J Physiol 274:R718-R724.

Countryman RA, Kaban NL, Colombo PJ (2005) Hippocampal c-fos is necessary for long-term memory of a socially transmitted food preference. Neurobiol Learn Mem 84:175-183.

Deshmukh SS, Bhalla US (2003) Representation of odor habituation and timing in the hippocampus. J Neurosci 23:1903-1915.

Dupret D, O’Neill J, Pleydell-Bouverie B, Csicsvari J (2010) The reorganization and reactivation of hippocampal maps predict spatial memory performance. Nat Neurosci 13:995-1002.

Eichenbaum H, Dudchenko P, Wood E, Shapiro M, Tanila H (1999) The hippocampus, memory, and place cells: is it spatial memory or a memory space? Neuron 23:209-226.

Fontanini A, Katz DB (2005) 7 to $12 \mathrm{hz}$ activity in rat gustatory cortex reflects disengagement from a fluid self-administration task. J Neurophysiol 93:2832-2840.

Fontanini A, Katz DB (2006) State-dependent modulation of time-varying gustatory responses. J Neurophysiol 96:3183-3193.

Fontanini A, Grossman SE, Figueroa JA, Katz DB (2009) Distinct subtypes of basolateral amygdala taste neurons reflect palatability and reward. J Neurosci 29:2486-2495.

Fox SE, Ranck JB Jr (1981) Electrophysiological characteristics of hippocampal complex-spike cells and theta cells. Exp Brain Res 41:399-410.

Frank LM, Brown EN (2003) Persistent activity and memory in the entorhinal cortex. Trends Neurosci 26:400-401.

Freund TF, Buzsáki G (1996) Interneurons of the hippocampus. Hippocampus 6:347-470.

Fried I, MacDonald KA, Wilson CL (1997) Single neuron activity in human hippocampus and amygdala during recognition of faces and objects. Neuron 18:753-765.

Fyhn M, Hafting T, Treves A, Moser MB, Moser EI (2007) Hippocampal remapping and grid realignment in entorhinal cortex. Nature 446:190194.

Geran LC, Travers SP (2009) Bitter-responsive gustatory neurons in the rat parabrachial nucleus. J Neurophysiol 101:1598-1612.

Grill HJ, Norgren R (1978) The taste reactivity test. I. Mimetic responses to gustatory stimuli in neurologically normal rats. Brain Res 143:263-279.

Grossman SE, Fontanini A, Wieskopf JS, Katz DB (2008) Learning-related plasticity of temporal coding in simultaneously recorded amygdalacortical ensembles. J Neurosci 28:2864-2873.

Haase L, Cerf-Ducastel B, Murphy C (2009) Cortical activation in response to pure taste stimuli during the physiological states of hunger and satiety. Neuroimage 44:1008-1021.

Hangya B, Li Y, Muller RU, Czurkó A (2010) Complementary spatial firing in place cell-interneuron pairs. J Physiol 588:4165-4175.

Harvey CD, Coen P, Tank DW (2012) Choice-specific sequences in parietal cortex during a virtual-navigation decision task. Nature 484:62-68.

Henriksen EJ, Colgin LL, Barnes CA, Witter MP, Moser MB, Moser EI (2010) Spatial representation along the proximodistal axis of CA1. Neuron 68:127-137.

Ho AS, Hori E, Nguyen PH, Urakawa S, Kondoh T, Torii K, Ono T, Nishijo H (2011) Hippocampal neuronal responses during signaled licking of gustatory stimuli in different contexts. Hippocampus 21:502-519.

Jadhav SP, Kemere C, German PW, Frank LM (2012) Awake hippocampal sharp-wave ripples support spatial memory. Science 336:1454-1458.

Jadhav SP, Rothschild G, Roumis DK, Frank LM (2016) Coordinated excitation and inhibition of prefrontal ensembles during awake hippocampal sharp-wave ripple events. Neuron 90:113-127.

Katz DB, Simon SA, Nicolelis MA (2001) Dynamic and multimodal responses of gustatory cortical neurons in awake rats. J Neurosci 21:44784489.
Kobayakawa T, Wakita M, Saito S, Gotow N, Sakai N, Ogawa H (2005) Location of the primary gustatory area in humans and its properties, studied by magnetoencephalography. Chem Senses 30:i226-227.

Kraus BJ, Robinson RJ 2nd, White JA, Eichenbaum H, Hasselmo ME (2013) Hippocampal "time cells": time versus path integration. Neuron 78:1090-1101.

Kullmann DM (2011) Interneuron networks in the hippocampus. Curr Opin Neurobiol 21:709-716.

Lavi K, Jacobson GA, Rosenblum K, Lüthi A (2018) Encoding of conditioned taste aversion in cortico-amygdala circuits. Cell Rep 24:278-283.

Leutgeb S, Leutgeb JK, Treves A, Moser MB, Moser EI (2004) Distinct ensemble codes in hippocampal areas CA3 and CA1. Science 305:1295-1298.

Leutgeb S, Leutgeb JK, Barnes CA, Moser EI, McNaughton BL, Moser MB (2005) Independent codes for spatial and episodic memory in hippocampal neuronal ensembles. Science 309:619-623.

Li J, Lemon CH (2015) Influence of stimulus and oral adaptation temperature on gustatory responses in central taste-sensitive neurons. J Neurophysiol 113:2700-2712.

Li JX, Yoshida T, Monk KJ, Katz DB (2013) Lateral hypothalamus contains two types of palatability-related taste responses with distinct dynamics. J Neurosci 33:9462-9473.

Li JX, Maier JX, Reid EE, Katz DB (2016) Sensory cortical activity is related to the selection of a rhythmic motor action pattern. J Neurosci 36:55965607.

Lisman J, Grace AA, Duzel E (2011) A neoHebbian framework for episodic memory; role of dopamine-dependent late LTP. Trends Neurosci 34: $536-547$.

MacDonald CJ, Meck WH, Simon SA (2012) Distinct neural ensembles in the rat gustatory cortex encode salt and water tastes. J Physiol 590:3169-3184.

Maier JX, Katz DB (2013) Neural dynamics in response to binary taste mixtures. J Neurophysiol 109:2108-2117.

Maier JX, Blankenship ML, Li JX, Katz DB (2015) A multisensory network for olfactory processing. Curr Biol 25:2642-2650.

Moita MA, Rosis S, Zhou Y, LeDoux JE, Blair HT (2003) Hippocampal place cells acquire location-specific responses to the conditioned stimulus during auditory fear conditioning. Neuron 37:485-497.

Moita MA, Rosis S, Zhou Y, LeDoux JE, Blair HT (2004) Putting fear in its place: remapping of hippocampal place cells during fear conditioning. J Neurosci 24:7015-7023

Monk KJ, Rubin BD, Keene JC, Katz DB (2014) Licking microstructure reveals rapid attenuation of neophobia. Chem Senses 39:203-213.

Morris R (1984) Developments of a water-maze procedure for studying spatial learning in the rat. J Neurosci Methods 11:47-60.

Moser EI, Kropff E, Moser MB (2008) Place cells, grid cells, and the brain's spatial representation system. Annu Rev Neurosci 31:69-89.

Nishijo H, Uwano T, Tamura R, Ono T (1998) Gustatory and multimodal neuronal responses in the amygdala during licking and discrimination of sensory stimuli in awake rats. J Neurophysiol 79:21-36.

O'Keefe J (1999) Do hippocampal pyramidal cells signal nonspatial as well as spatial information? Hippocampus 9:352-364.

O'Keefe J, Dostrovsky J (1971) The hippocampus as a spatial map: preliminary evidence from unit activity in the freely-moving rat. Brain Res 34: $171-175$.

O'Keefe J, Nadel L (1978) The hippocampus as a cognitive map. London: OUP.

Piette CE, Baez-Santiago MA, Reid EE, Katz DB, Moran A (2012) Inactivation of basolateral amygdala specifically eliminates palatability-related information in cortical sensory responses. J Neurosci 32:9981-9991.

Reilly S, Harley C, Revusky S (1993) Ibotenate lesions of the hippocampus enhance latent inhibition in conditioned taste aversion and increase resistance to extinction in conditioned taste preference. Behav Neurosci 107:996-1004.

Rosen AM, Roussin AT, Di Lorenzo PM (2010) Water as an independent taste modality. Front Neurosci 4:175.

Royer S, Zemelman BV, Losonczy A, Kim J, Chance F, Magee JC, Buzsáki G (2012) Nat Neurosci 15:769-775.

Sadacca BF, Katz DB (2011) Taste. In: Neurobiology of sensation and reward (Gottfriend JA, ed), pp 127-141. Boca Raton, FL: CRC/Taylor and Francis.

Sadacca BF, Rothwax JT, Katz DB (2012) Sodium concentration coding 
gives way to evaluative coding in cortex and amygdala. J Neurosci 32:9999-10011.

Sadacca BF, Mukherjee N, Vladusich T, Li JX, Katz DB, Miller P (2016) The behavioral relevance of cortical neural ensemble responses emerges suddenly. J Neurosci 36:655-669.

Shan KQ, Lubenov EV, Papadopoulou M, Siapas AG (2016) Spatial tuning and brain state account for dorsal hippocampal CA1 activity in a nonspatial learning task. eLife 5:e14321.

Shapiro ML, Tanila H, Eichenbaum H (1997) Cues that hippocampal place cells encode: dynamic and hierarchical representation of local and distal stimuli. Hippocampus 7:624-642.

Skaggs WE, McNaughton BL, Gothard K, Markus E (1993) An information theoretic approach to deciphering the hippocampal code. In: Advances in neural information processing systems (Hanson S, Cowan JD, Giles CL, eds), pp 1030-1037. San Mateo, CA: Morgan Kaufmann.

Spetter MS, Smeets PA, de Graaf C, Viergever MA (2010) Representation of sweet and salty taste intensity in the brain. Chem Senses 35:831-840.

Stone ME, Grimes BS, Katz DB (2005) Hippocampal inactivation enhances taste learning. Learn Mem 12:579-586.

Suzuki WA, Amaral DG (1994) Perirhinal and parahippocampal cortices of the macaque monkey: cortical afferents. J Comp Neurol 350:497-533.

Tang W, Shin JD, Frank LM, Jadhav SP (2017) Hippocampal-prefrontal reactivation during learning is stronger in awake compared with sleep states. J Neurosci 37:11789-11805.

Thompson LT, Best PJ (1990) Long-term stability of the place-field activity of single units recorded from the dorsal hippocampus of freely behaving rats. Brain Res 509:299-308.

Travers JB, Norgren R (1986) Electromyographic analysis of the ingestion and rejection of sapid stimuli in the rat. Behav Neurosci 100:544-555.

von Bohlen und Halbach O, Albrecht D (2002) Reciprocal connections of the hippocampal area CA1, the lateral nucleus of the amygdala and cortical areas in a combined horizontal slice preparation. Neurosci Res 44:91-100.

Wilent WB, Nitz DA (2007) Discrete place fields of hippocampal formation interneurons. J Neurophysiol 97:4152-4161.

Wood ER, Dudchenko PA, Eichenbaum H (1999) The global record of memory in hippocampal neuronal activity. Nature 397:613-616.

Yamamoto T, Fujimoto Y, Shimura T, Sakai N (1995) Conditioned taste aversion in rats with excitotoxic brain lesions. Neurosci Res 22:31-49.

Zald DH, Lee JT, Fluegel KW, Pardo JV (1998) Aversive gustatory stimulation activates limbic circuits in humans. Brain 121:1143-1154.

Zhang S, Manahan-Vaughan D (2015) Spatial olfactory learning contributes to place field formation in the hippocampus. Cereb Cortex 25:423432. 